\title{
Assessing the potential of the multi-aquifer subsurface of the Mekong Delta (Vietnam) for land subsidence due to groundwater extraction
}

\author{
P. S. J. Minderhoud ${ }^{1,2}$, G. Erkens ${ }^{2,1}$, V. H. Pham ${ }^{1,2,3}$, B. T. Vuong ${ }^{3}$, and E. Stouthamer ${ }^{1}$ \\ ${ }^{1}$ Department of Physical Geography, Utrecht University, Utrecht, the Netherlands \\ ${ }^{2}$ Department of Subsurface and Groundwater Systems, Deltares Research Institute, Utrecht, the Netherlands \\ ${ }^{3}$ Division of Water Resources Planning and Investigation for the South of Vietnam (DWRPIS), \\ Ho Chi Minh City, Vietnam
}

Correspondence to: P. S. J. Minderhoud (p.s.j.minderhoud@uu.nl)

Published: 12 November 2015

\begin{abstract}
Land subsidence rates of $\sim 1-4 \mathrm{~cm} \mathrm{yr}^{-1}$ are measured in the low-lying Vietnamese Mekong Delta. These relatively high subsidence rates are attributed to groundwater extraction, which has increased drastically over the past decades due to growing domestic, agricultural and industrial demands. As a result, hydraulic heads in aquifers are dropping, on average $0.3-0.7 \mathrm{~m} \mathrm{yr}^{-1}$. There is an urgent need to go from measurements to predictions in order to test possible future groundwater management scenarios and to reduce the increase of flood risk, salt water intrusion and, on the longer term, prevent the delta from drowning. In this study, we aim to assess the subsidence potential of the multi-aquifer subsurface of the Mekong delta due to groundwater extraction. The first step is to gain a thorough understanding of the complex sedimentary architecture of the heterogeneous subsurface. Combined with the related geotechnical properties, the subsurface build-up determines the subsidence potential. Here, we present our approach to develop a 3-D geo-hydrological model based on lithological borehole data, geophysical sedimentary properties, palaeogeography and conceptual models of delta evolution.
\end{abstract}

\section{Introduction}

The Vietnamese Mekong delta is experiencing strong intensifications of agricultural and aquaculture practices and cities in the delta are growing fast (Renaud and Kuenzer, 2012). Pressure on the existing natural resources is high and the demand for fresh water is steadily increasing. On daily basis over 2 million $\mathrm{m}^{3}$ of groundwater is extracted from the upper $500 \mathrm{~m}$ of the multi-aquifer subsurface. Aquifer drawdown occurs at rates of $0.3-0.7 \mathrm{~m} \mathrm{yr}^{-1}$ (Wagner et al., 2012). Such declines in hydraulic head can trigger high compaction in the drained subsurface sediments, causing land subsidence at the surface (e.g. Galloway and Burbey, 2011). However, the actual impact of groundwater extraction remains unclear, because: (1) subsidence rates measured at the surface are caused by multiple drivers, not just groundwater extraction, and (2) studies on subsidence in the Mekong delta are scarce and reliable ground-based, time series of land elevation are hard to find, if they at all exist. At present, InSAR data is the only source of surface elevation data available in time series, allowing the estimation of subsidence rates (Fig. 1).

Analysis of InSAR data measured during the period 20062010 reveals subsidence rates of $\sim 1-4 \mathrm{~cm} \mathrm{yr}^{-1}$ within the Mekong delta, with an average rate of $1.6 \mathrm{~cm} \mathrm{yr}^{-1}$ (Erban et al., 2014). These rates are high, especially when considering that the majority of the delta is elevated less than $2 \mathrm{~m}$ above mean sea level and already prone to flooding. Subsidence poses a real threat for the Mekong delta. Even more, if also absolute sea-level rise of $\sim 3 \mathrm{~mm} \mathrm{yr}^{-1}$ is taken into account (Church et al., 2013). Subsidence and absolute sea level rise determine relative sea level rise, the rise of mean sea level experienced from the land over time, increasing salt water intrusion and flood risks. Furthermore, subsidence is causing damage to buildings and infrastructure. There is an urgent need to come up with adequate groundwater quality and extraction regulation to secure a sustainable future for 


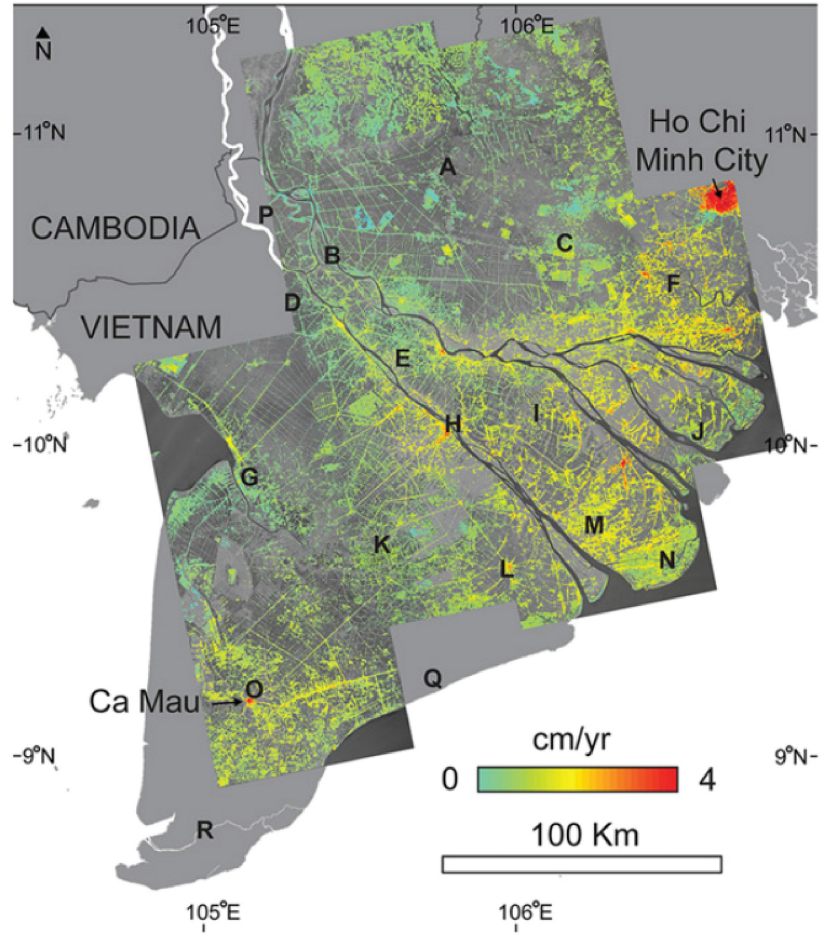

Figure 1. InSAR-based subsidence rates measured between 2006 and 2010 in the Mekong Delta. Locations of monitoring wells are marked by letters. Data ${ }^{\circledR}$ JAXA, METI 2011 (Erban et al., 2014).

the delta. Decision-making requires insights in the spatial extent and magnitude of groundwater extraction as driver of subsidence in the delta. Therefore, we aim to assess the subsidence potential of the upper $500 \mathrm{~m}$ of the subsurface due to groundwater extraction. The first step is to get a better understanding of the complex sedimentary architecture of the heterogeneous subsurface of the Mekong delta. In this paper we present our approach to develop a new 3-D subsurface model, which enables groundwater and subsidence modelling, based on thorough analysis of the complex multi-aquifer subsurface. Ultimately, this model can be used to create meaningful predictions and evaluate (ground)water management scenarios for policy-makers.

\section{From monitoring to predicting subsidence}

Total measured subsidence at the earth surface, e.g. by InSAR analysis, is the sum of subsidence resulting from all natural and human-induced drivers acting in an area (Fig. 2). This cumulative signal needs to be unraveled to determine the contribution of each driver and to go from measuring to predicting subsidence. We distinguish between shallow and deep drivers and processes of subsidence, because in the shallow phreatic aquifer other drivers and processes are dominant (e.g. drop in phreatic water table and consequent oxidation), than in the deeper confined aquifer-aquitard sys- tem (e.g. groundwater extraction causing consolidation). The boundary between shallow and deep processes depends on the local lithology and is situated at the top of the upper most aquitard. Total subsidence is the sum of all shallow and deep subsidence rates, resulting from all processes forced by all drivers of subsidence; the subsidence balance equation (Fig. 2). For the Mekong delta the subsidence balance equation is still unsolved and impacts of different drivers and processes are unknown. Erban et al. (2014) identified groundwater extraction as a potential main driver of subsidence, using 1-D consolidation calculations with hydraulic head time series at several locations in the delta. We will further explore the potential of groundwater extraction on subsidence for the Mekong delta in a step towards solving the total subsidence balance.

\section{Research approach}

Our first step to assess the subsidence potential of the multiaquifer system of the Mekong delta due to groundwater extraction, is to gain a profound understanding of the subsurface sedimentary architecture. The aquifer-aquitard architecture, the geotechnical properties and the characteristics and occurrence of interbeds will determine the potential for subsidence. Present models of the subsurface are coarse and do not have the level of detail required for accurate subsidence modelling (DWRPIS, 2010). Therefore we develop a 3-D lithological subsurface model based on a higher lithological data density and combining additional sources of subsurface data (Fig. 3). Furthermore, concepts of delta evolution and palaeogeographic development of the Mekong delta are constructed and provide valuable information on the spatial occurrence of palaeo-depositional environments. This allows to reconstruct the complex nature of the subsurface buildup through time. These insights are used to interpolate the lithological borehole data into a 3-D lithological subsurface model, in addition to standard interpolation methods, like linear interpolation of borehole data at point locations. Through this approach we create a more detailed and, from a geological point of view, more realistic representation of the complex multi-aquifer subsurface than present in current available models. Moreover, this approach enables exploration of aquifer characteristics such as aquifer connectivity and sediment properties. Subsequently, this lithological subsurface model is converted into a geo-hydrological model and transferred to a groundwater flow software package (e.g. MODFLOW), including a subsidence module. This enables hydrological and subsidence modelling of the Mekong delta at regional and local scales and assessing the subsidence potential of the subsurface by groundwater extraction. Finally, this model can be applied to create meaningful quantitative predictions of subsidence driven by groundwater extraction and evaluate groundwater management scenarios. 


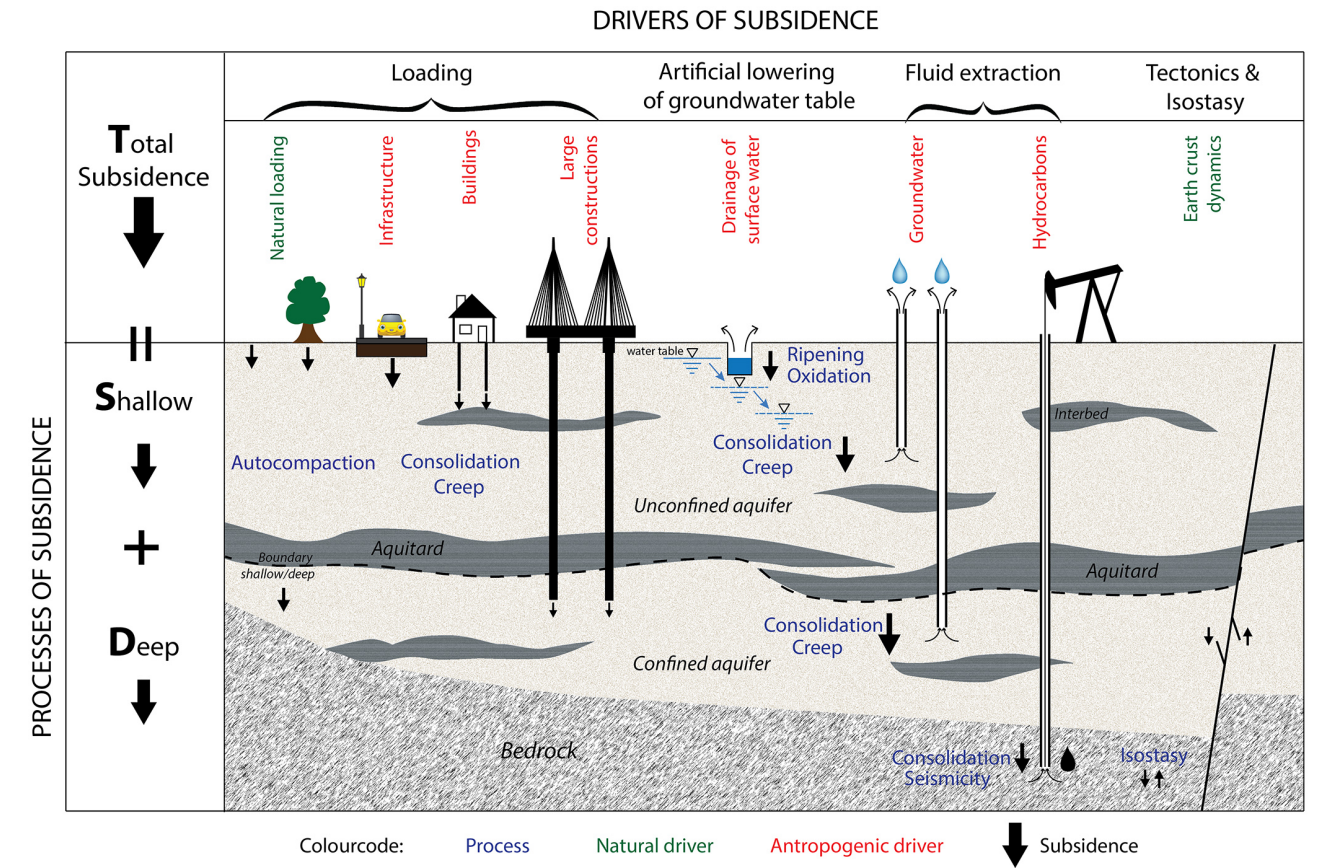

Figure 2. Schematization of the main subsidence drivers and processes within the upper (phreatic) aquifer and deeper (confined) aquifer(s). Natural and anthropogenic drivers are distinguished. The subsidence balance equation is given on the left side, being the total sum of all shallow and deep subsidence rates.

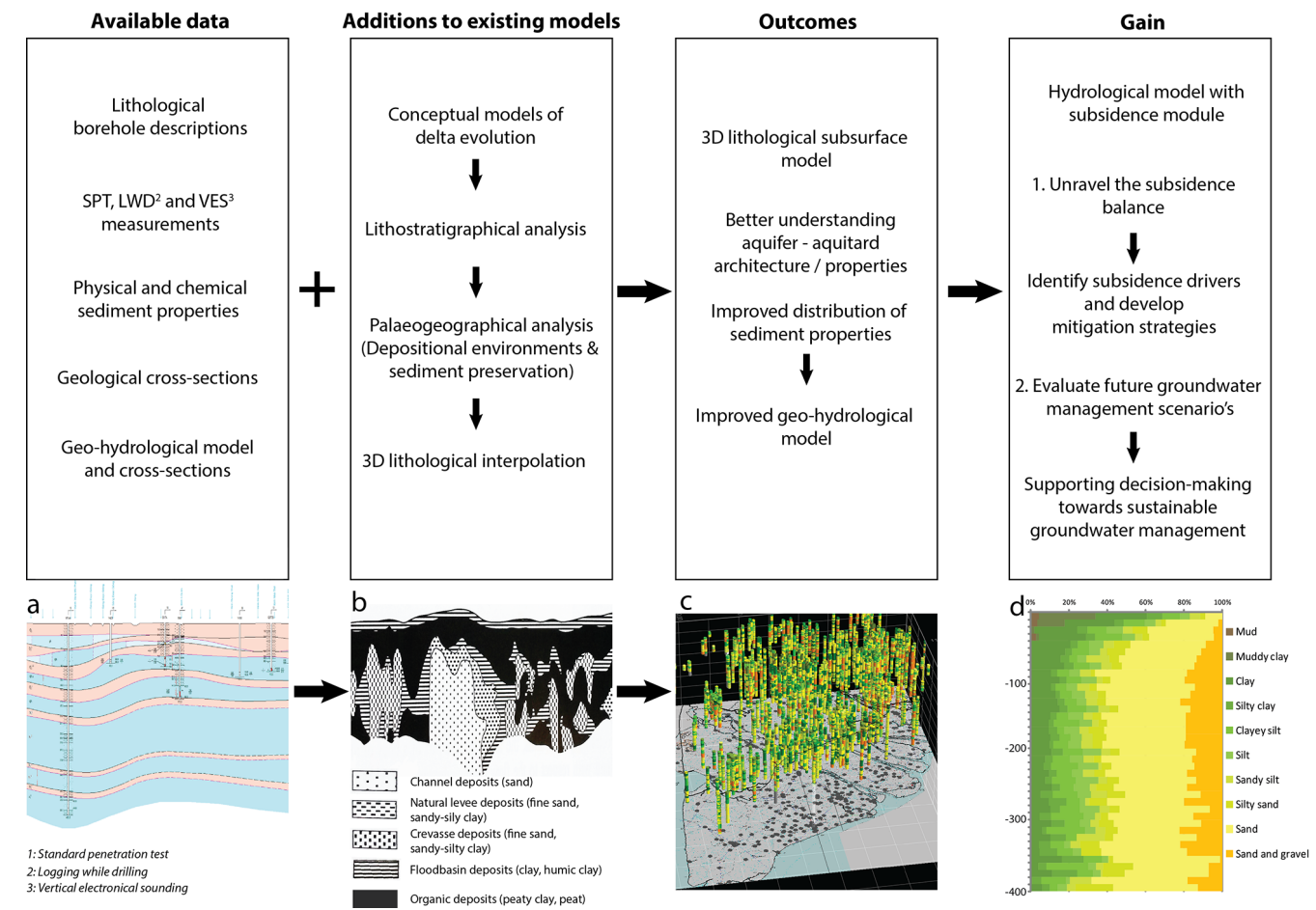

Figure 3. Workflow to develop the 3-D lithological subsurface model of the Mekong Delta, improve the geo-hydrological model and analyze the potential for subsidence driven by groundwater extraction. Steps graphically depicted below the workflow. (a) Cross-section of current geo-hydrological model. (b) Example of a cross-section including geomorphological elements as a result from lithological and palaeogeographical analyses (modified after Bierkens and Weerts, 1994). (c) 3-D view of the new available lithological borehole data in the Mekong delta up to $500 \mathrm{~m}$ deep. (d) Depth distribution of lithological classes for the Mekong delta. Data: ${ }^{\odot}$ Division of Water Resources Planning and Investigation of South Vietnam (DWRPIS). 


\section{Conclusions and future outlook}

Surface measurements by InSAR analysis show relatively high subsidence rates of $\sim 1-4 \mathrm{~cm} \mathrm{yr}^{-1}$ for the Mekong delta, causing increased flooding risk, salinization and damage to buildings and infrastructure. Groundwater extraction is hypothesized to be a main driver of subsidence, but the contribution of other possible human-induced drivers, like loading by buildings and infrastructure and drainage have not been quantified yet. The development of a new lithological model of the Mekong delta based on subsurface data and incorporating palaeogeographical and delta evolutional insights is the first step towards resolving the subsidence balance. The lithological model, converted into a 3-D geo-hydrological model, enables calculations of groundwater dynamics and resulting subsidence, using groundwater flow software including a subsidence module. This allows assessing the subsidence potential of the multi-aquifer system of the Mekong delta caused by groundwater extraction. The model can furthermore be used to create meaningful predictions of future subsidence rates using different delta management scenarios, supporting sustainable decision-making in groundwater management to limit the total amount and rates of subsidence

Acknowledgements. The Division of Water Resources Planning and Investigation for the South of Vietnam (DWRPIS), Ho Chi Minh city, Vietnam is thanked for providing subsurface and hydrological data for this research. This paper is part of a $\mathrm{PhD}$ research carried out by P. S. J. Minderhoud at the Department of Physical Geography, Utrecht University, The Netherlands. The PhD project is funded by NWO-WOTRO (W 07.69.105), Deltares and TNOGeological Survey of the Netherlands.

\section{References}

Bierkens, M. F. P. and Weerts, H. J. T.: Application of indicator simulation to modelling the lithological properties of a complex confining layer, Geoderma, 62, 265-284, doi:10.1016/00167061(94)90040, 1994.

Church, J. A., Clark, P. U., Cazenave, A., Gregory, J. M., Jevrejeva, S., Levermann, A., Merrifield, M. A., Milne, G. A., Nerem, R. S., Nunn, P. D., Payne, A. J., Pfeffer, W. T., Stammer, D., and Unnikrishnan, A. S.: Sea Level Change, in: Climate Change 2013: The Physical Science Basis. Contribution of Working Group I to the Fifth Assessment Report of the Intergovernmental Panel on Climate Change, edited by: Stocker, T. F., Qin, D., Plattner, G.K., Tignor, M., Allen, S. K., Boschung, J., Nauels, A., Xia, Y., Bex, V., and Midgley, P. M., Cambridge University Press, Cambridge, United Kingdom and New York, NY, USA, 2013.

DWRPIS (Division for Water Resources Planning and Investigation for the South): Report on the results of the National Groundwater Monitoring Network for Nam Bo Plain, Division of Water Resources and Planning Investigation of Viet Nam, unpublished, 2010.

Erban, L. E., Gorelick, S. M., and Zebker, H. A.: Groundwater extraction, land subsidence, and sea-level rise in the Mekong Delta, Vietnam, Environ. Res. Lett., 9, 1-6, doi:10.1088/17489326/9/8/084010, 2014.

Galloway, D. L. and Burbey, T. J.: Review: Regional land subsidence accompanying groundwater extraction, Hydrogeol. J., 19, 1459-1486, doi:10.1007/s10040-011-0775-5, 2011

Renaud, F. G. and Kuenzer, C.: The Mekong Delta System, Interdisciplinary analyses of a river delta, Springer, Dordrecht, Netherlands, 463 pp., doi:10.1007/978-94-007-3962-8, 2012.

Wagner, F., Tran, V. B., and Renaud, F. G.: Groundwater Resources in the Mekong Delta: Availability, Utilization and Risks, in: The Mekong Delta System, edited by: Renaud, F. G. and Kuenzer, C., Springer Environmental Science and Engineering, Springer Science+Business Media, Dordrecht, Netherlands, Chapter 7, 201-220, doi:10.1007/978-94-007-3962-8_7, 2012. 